\title{
In vivo Studies on Pharmacokinetics, Toxicity and Immunogenicity of Polyelectrolyte Nanocapsules Functionalized with Two Different Polymers: Poly-L-Glutamic Acid or PEG
}

This article was published in the following Dove Press journal: International Journal of Nanomedicine

\author{
Alicja Karabasz \\ Krzysztof Szczepanowicz $\mathbb{D}^{2}$ \\ Agnieszka Cierniak (D) ${ }^{3,4}$ \\ Renata Mezyk-Kopec (D) \\ Grzegorz Dyduch ${ }^{5}$ \\ Marta Szczęch (iD) ${ }^{2}$ \\ Joanna Bereta (D) \\ Monika Bzowska (ID) \\ 'Department of Cell Biochemistry, \\ Faculty of Biochemistry, Biophysics and \\ Biotechnology, Jagiellonian University, \\ Kraków, Poland; '2Jerzy Haber Institute of \\ Catalysis and Surface Chemistry, Polish \\ Academy of Sciences, Kraków, Poland; \\ ${ }^{3}$ Department of General Biochemistry, \\ Faculty of Biochemistry, Biophysics and \\ Biotechnology, Jagiellonian University, \\ Kraków, Poland; ${ }^{4}$ Department of \\ Biochemistry, Faculty of Medicine and \\ Health Sciences, Andrzej Frycz \\ Modrzewski Krakow University, Kraków, \\ Poland; ${ }^{5}$ Department of \\ Pathomorphology, Jagiellonian University \\ Medical College, Kraków, Poland
}

Correspondence: Monika Bzowska Department of Cell Biochemistry, Faculty of Biochemistry, Jagiellonian University in Kraków, Biophysics and Biotechnology, 7 Gronostajowa Street, Kraków 30-387,

Poland

Tel/Fax +48 I2 6646388

Email monika.bzowska@uj.edu.pl
Background: The functionalization of a nanoparticle surface with PEG (polyethylene glycol) is an approach most often used for extending nanomaterial circulation time, enhancing its delivery and retention in the target tissues, and decreasing systemic toxicity of nanocarriers and their cargos. However, because PEGylated nanomedicines were reported to induce immune response including production of anti-PEG antibodies, activation of the complement system as well as hypersensitivity reactions, hydrophilic polymers other than PEG are gaining interest as its replacement in nanomaterial functionalization. Here, we present the results of in vivo evaluation of polyelectrolyte nanocapsules with biodegradable, polyelectrolyte multilayer shells consisting of poly-L-lysine (PLL) and poly-L-glutamic (PGA) acid as a potential drug delivery system. We compared the effects of nanocapsules functionalized with two different "stealth" polymers as the external layer of tested nanocapsules was composed of PGA (PGA-terminated nanocapsules, NC-PGA) or the copolymer of poly-L-lysine and polyethylene glycol (PEG-terminated nanocapsules, NC-PEG).

Methods: Nanocapsules pharmacokinetics, biodistribution and routes of eliminations were analysed postmortem by fluorescence intensity measurement. Toxicity of intravenously injected nanocapsules was evaluated with analyses of blood morphology and biochemistry and by histological tissue analysis. DNA integrity was determined by comet assay, cytokine profiling was performed using flow cytometer and detection of antibodies specific to PEG was performed by ELISA assay.

Results: We found that NC-PGA and NC-PEG had similar pharmacokinetic and biodistribution profiles and both were eliminated by hepatobiliary and renal clearance. Biochemical and histopathological evaluation of long-term toxicity performed after a single as well as repeated intravenous injections of nanomaterials demonstrated that neither NC-PGA nor NC-PEG had any acute or chronic hemato-, hepato- or nephrotoxic effects. In contrast to NC-PGA, repeated administration of NC-PEG resulted in prolonged increased serum levels of a number of cytokines.

Conclusion: Our results indicate that NC-PEG may cause undesirable activation of the immune system. Therefore, PGA compares favorably with PEG in equipping nanomaterials with stealth properties. Our research points to the importance of a thorough assessment of the potential influence of nanomaterials on the immune system.

Keywords: polyelectrolyte nanocapsules, stealth polymers, animal studies

\section{Introduction}

Medical application of nanomaterials is becoming increasingly important in diagnostics as well as in prophylaxis and treatment of various diseases. Currently, most 
clinically approved nanotherapeutics belong to liposomes and polymeric nanoparticles, which includes PEGylated proteins and aptamers, however the number of nanomaterials accepted by the Food and Drug Administration (FDA) for medical application is still low. ${ }^{1}$ The potential use of new drug nanocarriers requires prior detailed studies of their pharmacokinetics, biodistribution, and routes of elimination to ensure the highest efficiency of transported compounds. Due to the vascular structure of the liver, spleen, and kidneys, nanomaterials accumulate predominantly in these organs; however, the pharmacokinetics and biodistribution of nanoparticles depend also on a particle size, shape, surface charge and decoration, deformability, and degradability. ${ }^{2}$

Toxicity of potential nanotherapeutics is the most common cause that hinders their use in medicine, thus all possible adverse effects must be addressed during their thorough preclinical evaluation. First of all, the influence of nanomaterials on the organs in which they accumulate and which participate in their removal should be investigated. A growing body of research showed that exposure of animals to inorganic nanoparticles often results in DNA damage, induction of inflammation, alterations in blood morphology, hepatotoxicity, or nephrotoxicity. ${ }^{3-6}$ Biodegradable nanoparticles built of organic components that are decomposed into nontoxic products are considered less toxic and thus safer than carbonbased or inorganic nanoparticles. ${ }^{7}$ There are a limited number of studies that analyze the possible toxicity of biodegradable nanocarriers in vivo. For example, low in vivo toxicity was demonstrated for poly(ć-caprolactone) lipid-core nanocapsules, nanoparticles made of biotransestrified $\beta$-cyclodextrins, and PEGylated phospholipids. ${ }^{8,9}$ However, many new, promising biodegradable nanomaterials still await meticulous biodistribution and toxicity analyses required prior to their potential medical applications. ${ }^{10-12}$

Modification of nanoparticle surface with hydrophilic stealth polymers is a recognized method for improving nanomaterial pharmacokinetic properties, enhancing retention in target tissues and reducing systemic toxicity of nanocarriers and their cargos. ${ }^{13,14}$ Polyethylene glycol (PEG) has been most oftenly used for nanoparticle coating; however, other polymers, including poly[N-(2-hydroxypropyl)methacrylamide], poly(carboxybetaine), poly(hydroxyethyl-L-asparagine) or poly-L-glutamic acid, are increasingly being considered as better replacements. ${ }^{15}$

We have previously developed polyelectrolyte nanocapsules produced by encapsulation of nanoemulsion droplets in shells formed of poly-amino acids, poly-L-lysine
(PLL) and poly-L-glutamic acid (PGA), using layer-bylayer method, as a promising candidate for medical applications. We confirmed that different drugs encapsulated in tested nanomaterials including anticancer-, neuroprotective-, or antipsychotic ones had similar activity to free drugs. ${ }^{16-20}$ Therefore, their application might limit systemic side effects of enclosed therapeutic while maintaining their medical effectiveness. We also performed detailed in vitro toxicity analysis of the nanocapsules functionalized with PGA or PEG and confirmed the lack of deleterious effects towards cultured cells. ${ }^{21}$ Here, we present the results of in vivo evaluation of nanocapsules with an external layer composed of PGA (PGA-terminated nanocapsules, NC-PGA) or with an external layer composed of the copolymer of poly-L-lysine and polyethylene glycol (PEG-terminated nanocapsules, NC-PEG). We studied nanocapsules' properties in a mouse model including their pharmacokinetic and biodistribution profiles, routes of elimination, short- and long-term toxicity, and their impact on the immune system. We demonstrated for the first time that PEGylated biodegradable nanocapsules may cause prolonged elevated serum levels of a set of cytokines, indicating undesired activation of the immune system and pointed to immunologically inert PGA as a promising alternative for nanomaterial functionalization.

\section{Materials and Methods Chemicals}

Biocompatible polyelectrolytes used for preparation of nanocapsules were: polycation poly-L-lysine hydrobromide (PLL, MW 15,000-30,000), and polyanion poly-L-glutamic acid sodium salt (PGA, MW 15,000-50,000). Polyelectrolytes, docusate sodium salt (AOT), chloroform, and sodium chloride were obtained from Sigma-Aldrich. PEGylated polyelectrolyte poly(L-lysine)-graft-poly(ethylene glycol), PLL (20,000)-g-PEG(5000), was purchased from SuSoS (Dübendorf, Switzerland). Poly-L-lysine fluorescently labeled with rhodamine B (PLL-RhB) was synthesized via coupling of Lissamine rhodamine B sulfonyl chloride with poly-L-lysine hydrobromide according to the protocol. ${ }^{22}$ Poly (L-glutamine)-graft-poly(ethylene glycol) (PGA-g-PEG) was synthesized previously by Szczepanowicz et al. ${ }^{23}$ The obtained coupling rate of approximately $31 \%$ corresponded to a grafting ratio of $g=3.2$. Ultrapure water was obtained using the Millipore Direct-Q5 UV purification system. Reagents used for histological analysis: formaldehyde solution 4\%, buffered, pH 6.9 and eosin Y solution, alcoholic, 
with phloxine were from Merck (Darmstadt, Germany); hematoxylin stain solution, modified Harris formulation, and xylene were from VWR International (Radnor, U.S.). Ethanol solution 99.9\% was purchased from Chempur (Piekary Śląskie, Poland). Horseradish peroxidase (HRP)conjugated polyclonal goat anti-mouse Ig antibody was from BD Pharmingen (San Jose, U.S.). Rabbit antipolyethylene glycol antibodies [26A04] and goat anti-rabbit IgM antibodies conjugated to HRP were from Abcam (Cambridge, Great Britain).

\section{Preparation and Characterization of Nanocapsules}

The following polyelectrolyte nanocarriers were synthesized by the encapsulation of nanoemulsion droplets in polyelectrolyte multilayer shell: NC-PGA (PGA-terminated six-layer polyelectrolyte nanocapsules), NC-PEG (PEG-terminated seven-layer polyelectrolyte nanocapsules) for toxicity analyses and NC-PGA-RhB (fluorescently labeled PGA-terminated six-layer polyelectrolyte nanocapsules), NC-PEG-RhB (fluorescently labeled PEG-terminated seven-layer polyelectrolyte nanocapsules) for pharmacokinetic and biodistribution analyses. This method has been described in detail in our previous papers. ${ }^{21}$ Briefly, nanoemulsion droplets were formed by dispersing $0.1 \mathrm{~mL}$ of oil phase $(34 \mathrm{mg} / \mathrm{mL}$ AOT dissolved in chloroform) into $200 \mathrm{~mL}$ aqueous polycation solution $(0.1 \mathrm{mg} /$ $\mathrm{mL}$ in $15 \mathrm{mM} \mathrm{NaCl}$ ). Subsequently, nanoemulsion droplets were encapsulated in a polyelectrolyte shell by a layer-bylayer technique using a saturation approach. The volumes of polyelectrolytes (PLL, PGA, PLL-RhB, PLL-g-PEG) used for the formation of consecutive layers of the multilayer shell are available in Supplementary material (Table S1 in Supplementary material). The synthesized nanocapsules were characterized by measurements of their size, concentration and zeta potential. The size and zeta potential of nanocapsules were determined by Dynamic Light Scattering (DLS) and Laser Doppler Electrophoresis (LDV) technique using Zetasizer Nano Series from Malvern Panalytical Instruments. The concentrations of nanocapsules were determined by Nanoparticle Tracking Analysis using NanoSight NS500 (Malvern Panalytical Instruments). The values of all nanocapsules' parameters were averages of at least three measurements performed at $25^{\circ} \mathrm{C}$ against $15 \mathrm{mM} \mathrm{NaCl}$. The stability of nanocapsules in serum was determined previously. ${ }^{24}$ Contamination of nanocapsules with lipopolysaccharide (LPS) was excluded with a method based on the detection of NO (nitrate oxide) produced by murine primary endothelial cells and macrophages in response to nanocapsules and cytokines. $^{21}$

\section{Animals}

All in vivo experiments were performed using BALB/c female, 5- to 6-week-old mice purchased from the Center of Experimental Medicine of the Medical University of Białystok, Poland. Animals were housed under controlled conditions, 12-12 hrs light-dark cycle and provided with food and water ad libitum. All animal procedures were performed pursuant to Polish law, and specifically to the Act on the Protection of Animals used for Scientific or Educational Purposes (D20150266L), which implements the Directive of the European Parliament and the Council (2010/63/EU). The experimental work was in agreement with the guidelines of the Institutional Animal Care and Use Committee (IACUC) and was approved by the 2 nd Local IACUC in Kraków.

\section{Nanomaterial Pharmacokinetics and Biodistribution Studies}

Administration of Fluorescently Labeled Nanocapsules

Prior to experiments, the animals were randomly divided into three groups $(n=5-6)$ and weighted. Mice in the individual groups were injected $(100 \mu \mathrm{L}$ per $10 \mathrm{~g}$ of body weight) with: i) $15 \mathrm{mM} \mathrm{NaCl}$ (autofluorescence control) or fluorescently labeled nanocapsules: ii) NC-PGA-RhB or iii) NC-PEG-RhB in a single dose via the lateral tail vein. The concentrations of NC-PGA-RhB and NC-PEG-RhB were $2.5 \times 10^{10}$ nanocapsules $/ \mathrm{mL}$. To compare pharmacokinetic and biodistribution profiles of both types of nanocapsules, we confirmed that their fluorescence intensities in $\mathrm{NaCl}$ or tissue homogenates were comparable.

Collection of Serum, Bile, and Organs After Intravenous Administration of Rhodamine-Labeled Nanocapsules and Analysis of Their Fluorescence

The animals were euthanized via intraperitoneal administration of ketamine ( $50 \mathrm{mg} / \mathrm{kg}$ of body weight) and xylazine (5 mg/kg of body weight) $3,15,30,60,240 \mathrm{mins}$ or $24 \mathrm{hrs}$ after administration of the nanocapsules. Blood was collected by a cardiac puncture, allowed to clot (for $30 \mathrm{mins}$ ), and centrifuged ( $2800 \mathrm{RCF}, 10 \mathrm{mins}, \mathrm{RT}$ ) in order to separate serum. Bile was collected postmortem from gall bladders. Isolated organs (liver, spleen, kidneys, heart, lungs, thymus, thyroid and brain) were weighted and homogenized in PBS $\left(0.1 \mathrm{~g}\right.$ of tissue per $1 \mathrm{~mL}$ of PBS) using gentleMACS ${ }^{\mathrm{TM}}$ Dissociator and gentleMACS ${ }^{\text {TM }} \mathrm{M}$ tubes (Miltenyi Biotec). 
Aliquots of $100 \mu$ Lof serum, homogenized organs and diluted bile (1:100 in PBS) were transferred into 96-well black microplates. Urine and feceswere also collected as described below. Fluorescence intensity was measured at $590 \mathrm{~nm}$ after excitation at $560 \mathrm{~nm}$ using Synergy H1 hybrid reader and analyzed with Gene5 Software (BIOTEK Instruments).

Analysis of the Nanocapsule Biodistribution and Routes of Clearance (Urine and Feces Collection)

To collect urine and feces individually from each mouse, mice were placed in metabolic cages for a single mouse (Tecniplast) immediately after nanomaterial injection in accordance with the conditions for animal care recommended by the IACUC. The urine samples were collected after each spontaneous urination for the first 10 hrs and then after $24 \mathrm{hrs}$ (just before euthanasia). Fluorescence of separate samples was measured immediately after their collection. Next, all urine samples from one animal were pooled, the volume was recorded and fluorescence of $100 \mu \mathrm{L}$ of this 24-hrs urine sample was analyzed. Similarly, feces were collected every 1 $\mathrm{hr}$ for the first $10 \mathrm{hrs}$ after nanocapsule administration, then after $24 \mathrm{hrs}$, and at euthanasia. Collected feces were pooled. Feces were weighted, resuspended in PBS at $37^{\circ}$ C ( $0.1 \mathrm{~g}$ of feces $/ 1 \mathrm{~mL}$ of PBS) and centrifuged (2800 $\mathrm{RCF}, 5$ mins, RT). Aliquots of $100 \mu \mathrm{L}$ of urine and resuspended feces were transferred into 96-well black microplates. Fluorescence intensity was measured at $590 \mathrm{~nm}$ after excitation at $560 \mathrm{~nm}$ using Synergy H1 hybrid reader and analyzed with Gene5 Software (BIOTEK Instruments).

\section{Detected Dose Parameter}

The detected dose corresponds to the total fluorescence, which is the sum of all the fluorescence values measured for total serum, bile and all the organs 3 mins after the nanocapsule administration reduced by the background fluorescence signals derived from control mice injected with $15 \mathrm{mM} \mathrm{NaCl}$ (autofluorescence measured for each tissue or fluid). The fluorescence of individual organs, urine, bile and serum (defined as fluorescence of sample in the following formula) has been calculated for the entire organ or physiological fluid (after taking into account its mass or volume). A parameter quantitating nanomaterial biodistribution was defined as the percent of the detected dose ( $\%$ detected dose, $\% \mathrm{DD})$ and calculated according to the formula:

$$
\begin{aligned}
\% \text { detected dose }= & \frac{\text { fluorescence of sample }}{\text { detected dose }(\text { total fluorescence })} \\
& \times 100 \% .
\end{aligned}
$$

\section{Analysis of in vivo Toxicity}

Prior to the experiments, all animals were weighted and randomly divided into three experimental groups $(n=5)$. Mice were injected intravenously (in the tail vein) on day 0 of experiment with i) $15 \mathrm{mM} \mathrm{NaCl}$, ii) NC-PGA or iii) NC-PEG $(100 \mu \mathrm{L} / 10 \mathrm{~g}$ of body weight, nanocapsule concentration was $\sim 2.5 \times 10^{10}$ nanocapsules $/ \mathrm{mL}$ ). There were two schemes of the experiment: i) a single administration of $\mathrm{NaCl}$ or NC-PEG and ii) multiple administrations (8 injections performed every fourth day) of $\mathrm{NaCl}, \mathrm{NC}-\mathrm{PGA}$ or NC-PEG. In a single administration protocol, animals were sacrificed at $24 \mathrm{hrs}$ after the nanocapsule administration (1st day of experiment) or on 7th, 30th, 60th day of experiment. In the case of the multiple injections protocol, animals were euthanized at $24 \mathrm{hrs}$ or 30 days after the last administration (30th and 60th day of experiment). The behavior of the animals was closely monitored for several hours after the administration of the nanomaterial to exclude acute toxicity. Immediately before euthanasia, venous blood samples were collected from the facial vein to EDTA tubes (Microvette, Sarstedt) in order to analyze hematological parameters. Blood for other tests and organs was collected postmortem. Organs were weighted and placed in $4 \%$ formaldehyde for histological analysis. The organ-to-body mass indexes were calculated.

\section{Hematological Analysis}

Blood samples were analyzed using a veterinary hematology analyzer $\mathrm{ABC}$ Vet $\left(\mathrm{HORIBA}^{\circledR}\right.$, UK). The following parameters were determined: counts of white blood cells, red blood cells, platelets, granulocytes, lymphocytes, and monocytes, hematocrit, mean corpuscular volume, hemoglobin concentration, and red cell distribution width.

\section{Serum Biochemical Analyses}

The samples of sera obtained from blood collected via a cardiac puncture were stored at $-20^{\circ} \mathrm{C}$. Biochemical parameters were measured using Spotchem EZ Chemistry Analyzer (Woodley) and multiparameter strips: Spotchem II Panel V, according to the manufacturer's instructions. The concentration or activity of the following compounds was analyzed: alkaline phosphatase, alanine transaminase, creatinine, total protein, blood urea nitrogen. 


\section{Cytokine Profiling}

Cytokines' (IL-1 $\alpha$, IL-1 $\beta$, IL-6, IL-10, IL-12p70, IL-17 $\alpha$, IL-23, IL-27, MCP-1, IFN- $\beta$, IFN- $\gamma$, TNF- $\alpha$, and GM$\mathrm{CSF}$ ) concentrations in sera were determined using LEGENDplex Mouse Inflammation Panel (13-plex) kit (Biolegend) and the BD LSRFortessa flow cytometer. The results were analyzed using LEGENDplex software (Biolegend).

Analysis of Immune Response to PEGylated Nanomaterial; Detection of Antibodies Specific to PEG Using Direct ELISA on Copolymer PGA-g-PEG

ELISA plates were coated with $100 \mu \mathrm{L}$ of copolymer PGA-g-PEG diluted $1: 20$ in PBS $\left(37^{\circ} \mathrm{C}, 30 \mathrm{mins}\right)$ and blocked $\left(37^{\circ} \mathrm{C}, 1 \mathrm{hr}\right)$ with $200 \mu \mathrm{L}$ of blocking solution ( $2 \%$ bovine serum albumin (BSA) in PBS). Next, $50 \mu \mathrm{L}$ aliquots of diluted sera (1:20 in the blocking solution) or control rabbit anti-PEG IgM $(0.06 \mu \mathrm{g} / \mathrm{mL})$ were added to the wells for $1 \mathrm{hr}\left(37^{\circ} \mathrm{C}\right)$. The level of antibodies attached to the antigen was probed with goat polyclonal anti-mouse Ig conjugated to HRP (diluted 1:3000 in blocking solution) or goat polyclonal anti-rabbit IgM conjugated to HRP (to detect rabbit anti-PEG antibody used as a positive control of the test, diluted 1:10,000 in blocking solution) (incubation $\left.30 \mathrm{mins}, 37^{\circ} \mathrm{C}\right)$. Each step of the test was followed by washing the wells with $200 \mu \mathrm{L}$ of PBS (6×). The enzymatic reaction was performed using TBM substrate reagent kit (BD). The absorbance was measured at 450 $\mathrm{nm}$ using Synergy H1 hybrid reader and analyzed with Gene5 Software.

\section{Analysis of in vivo Genotoxicity - Comet Assay}

Bone marrow cells were isolated postmortem from animals exposed to nanocapsules by flushing femurs with PBS. Mouse peritoneal cells were collected by flushing peritoneal cavities with PBS. Analysis of DNA damage in isolated cells $\left(1 \times 10^{5}\right.$ cells $/ 100 \mu \mathrm{L}$ of PBS $)$ was performed according to the procedure described previously. ${ }^{21}$ The percentage of DNA in the comet tail (\% DNA damage) was determined from two slides per sample with 50 randomly selected cells per slide.

\section{Histological Analysis}

For histological analysis, major organs including the liver, spleen and kidneys were collected from mice, fixed in $4 \%$ paraformaldehyde, embedded in paraffin, sectioned into 4 $\mu \mathrm{m}$ slices and stained with hematoxylin/eosin (H\&E).

\section{Statistical Analysis}

Statistical significance was performed for all results by the multiple $t$-test with the use of GraphPad Prism 6, with $\mathrm{P}<0.05$ being considered significant.

\section{Results}

\section{Characterization of Nanocapsules}

Various types of polyelectrolyte nanocapsules were synthesized by the encapsulation of nanoemulsion droplets in polyelectrolyte multilayer shell. The biocompatible polyelectrolytes PGA and PLL were used to construct multilayer shell (Figure S1A in Supplementary materials). We used in our study PGA-terminated six-layer nanocapsules (NC-PGA) or the PEGylated nanocapsules with an additional layer of a copolymer of poly-L-lysine and polyethylene glycol (NC-PEG). For the preparation of fluorescently labeled nanocapsules, the fluorescently labeled polycation PLL-RhB was used instead of the PLL layer. The synthesized nanocapsules were characterized by measurements of their size, concentration and zeta potential as summarized in Table 1. We confirmed that the sizes of all synthesized nanocapsules were comparable, approximately 120 to $140 \mathrm{~nm}$.

\section{NC-PGA-RhB Have Identical Pharmacokinetic Profile to NC-PEG-RhB}

In order to analyze pharmacokinetic profiles of the nanomaterials, we injected mice intravenously with fluorescently labeled nanocapsules, NC-PGA-RhB or NC-PEG-RhB and analyzed their fluorescence in serum and major internal organs collected at different times after treatment. As illustrated in Figure 1, kinetics of fluorescence intensity showed similar biphasic clearance of both nanocapsule types from circulation with the initial fast distribution phase and the subsequent slow phase monitored up to 240 mins. The highest fluorescence intensity in serum was measured approximately 3 mins after nanomaterial administration. After 240 mins fluorescence was still detectable, although its intensity was very low $(0.29 \%$ of DD for NC-PGA-RhB and $0.16 \%$ of DD for NC-PEG-RhB) indicating almost complete nanocapsule clearance from the blood. The fluorescence corresponding to nanocapsules was also detectable in the liver, spleen, and kidneys. In 3 mins after nanomaterial administration, the fluorescence signals of both nanocapsule types in the liver were similar to those in serum, indicating rapid liver accumulation of the nanocapsules (Figure 2). The fluorescence intensities in the liver were stabilized after 30 
Table I Characterization of Synthesized Nanocapsules

\begin{tabular}{|c|c|c|c|c|}
\hline Name & Abbreviation & $\begin{array}{l}\text { Size } \pm \text { SD } \\
{[\mathrm{nm}]}\end{array}$ & $\begin{array}{l}\text { Zeta } \pm \text { SD } \\
{[\mathrm{mV}]}\end{array}$ & $\begin{array}{l}\text { Concentration } \pm \text { SD } \\
\text { [Nanoparticles } / \mathrm{mL}]\end{array}$ \\
\hline PGA-terminated six-layered polyelectrolyte nanocapsules & NC-PGA & $120 \pm 15$ & $-42 \pm 2$ & $\sim 5 \times 10^{10} \pm 3.5 \times 10^{7}$ \\
\hline PEG-terminated seven-layered polyelectrolyte nanocapsules & NC-PEG & $140 \pm 12$ & $3.6 \pm 3$ & $2.5 \times 10^{10} \pm 1.9 \times 10^{7}$ \\
\hline $\begin{array}{l}\text { Fluorescently labeled PGA-terminated six-layered } \\
\text { polyelectrolyte nanocapsules }\end{array}$ & NC-PGA-RhB & $120 \pm 20$ & $-4 \mid \pm 3$ & $\sim 5 \times 10^{10} \pm 2.4 \times 10^{7}$ \\
\hline $\begin{array}{l}\text { Fluorescently labeled PEG-terminated seven-layered } \\
\text { polyelectrolyte nanocapsules }\end{array}$ & NC-PEG-RhB & $140 \pm 10$ & $3.2 \pm 4$ & $\sim 2.5 \times 10^{10} \pm 5.1 \times 10^{7}$ \\
\hline
\end{tabular}

Abbreviation: SD, standard deviation.

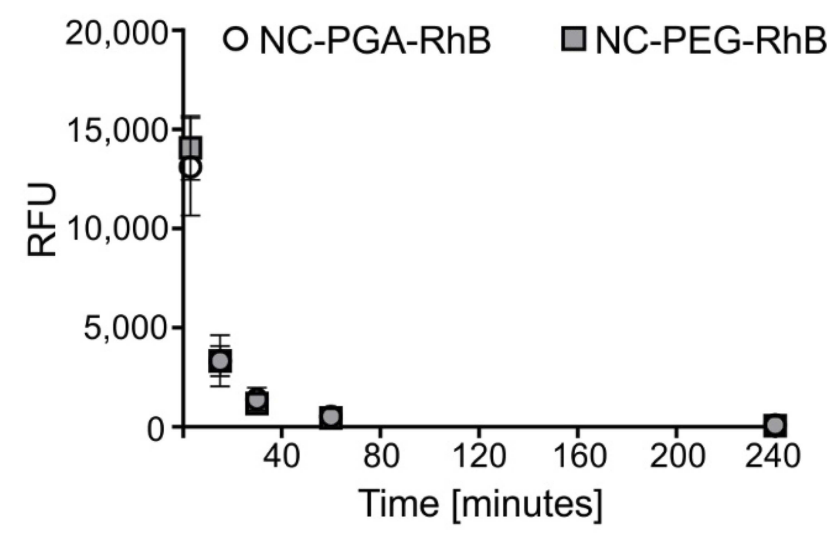

Figure I Pharmacokinetic profiles of fluorescently labeled polyelectrolyte nanocapsules in serum after intravenous administration.

Notes: NC-PGA-RhB or NC-PEG-RhB nanocapsules were injected intravenously. Fluorescence was measured in sera obtained at different time points after administration, and the value corresponding to serum autofluorescence was subtracted. Each point in the graph represents the mean $\pm S D(n=6)$.

mins and remained at the same level also after 60,120 and 240 mins. Similarly, rapid decreases of the fluorescence intensities were observed in the kidneys between 3 and 30 mins after nanocapsule administration. The stable, low signals were acquired after 60 mins and 120 mins, and the fluorescence was still detectable after 240 mins in kidneys. In contrast, fluorescence intensities in the spleen were at the same level throughout the observation period. Four hours after nanocapsule administration, the liver showed the highest fluorescence intensities among organs, followed by the spleen and kidneys with decreasing values.

\section{NC-PGA-RhB Have Identical Biodistribution Profile and Elimination Routes to NC-PEG-RhB}

The animals were placed in separate metabolic cages immediately after nanomaterial injection to enable urine and feces collection for the analysis of elimination routes. The biodistribution of fluorescently labeled nanocapsules in blood, tissues, and bile was analyzed $24 \mathrm{hrs}$ after injection. As presented in Figure 3, the highest fluorescence signals

\section{O NC-PGA-RhB $\square$ NC-PEG-RhB}
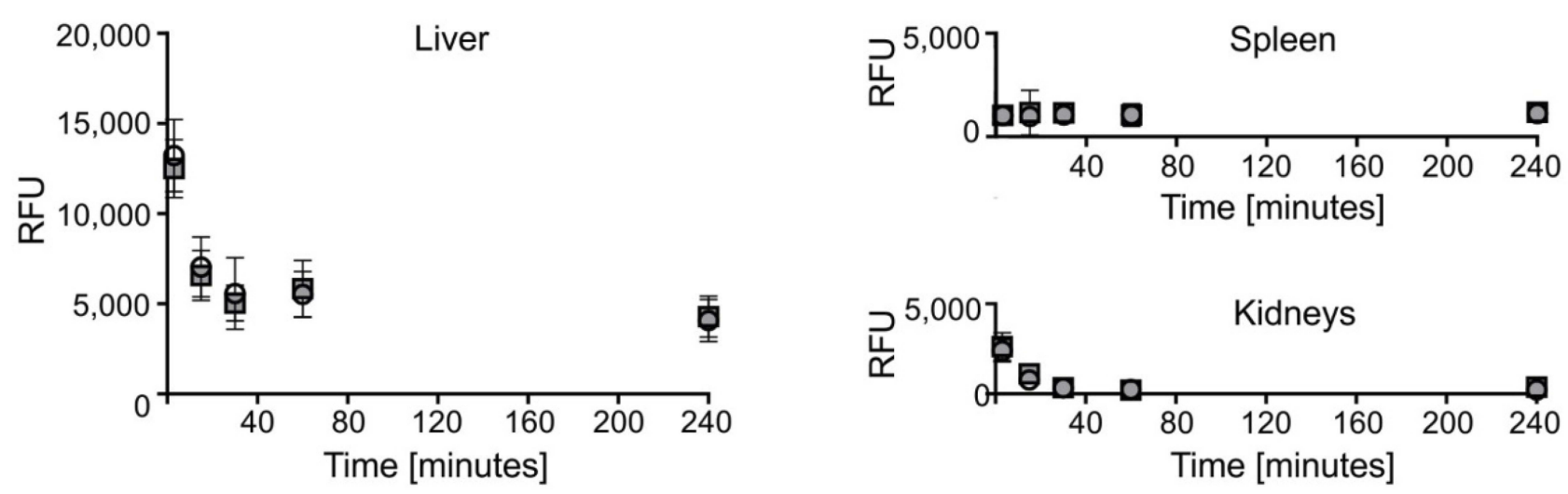

Figure 2 Pharmacokinetic profiles of fluorescently labeled polyelectrolyte nanocapsules in the liver, spleen, and kidneys after intravenous administration. NC-PGA-RhB and NC-PEG-RhB were injected intravenously.

Notes: Fluorescence was measured in organs' homogenates obtained at different time points after administration, and autofluorescence corresponding to control homogenates was subtracted. Each point in the graphs represents the mean $\pm S D(n=5)$. 


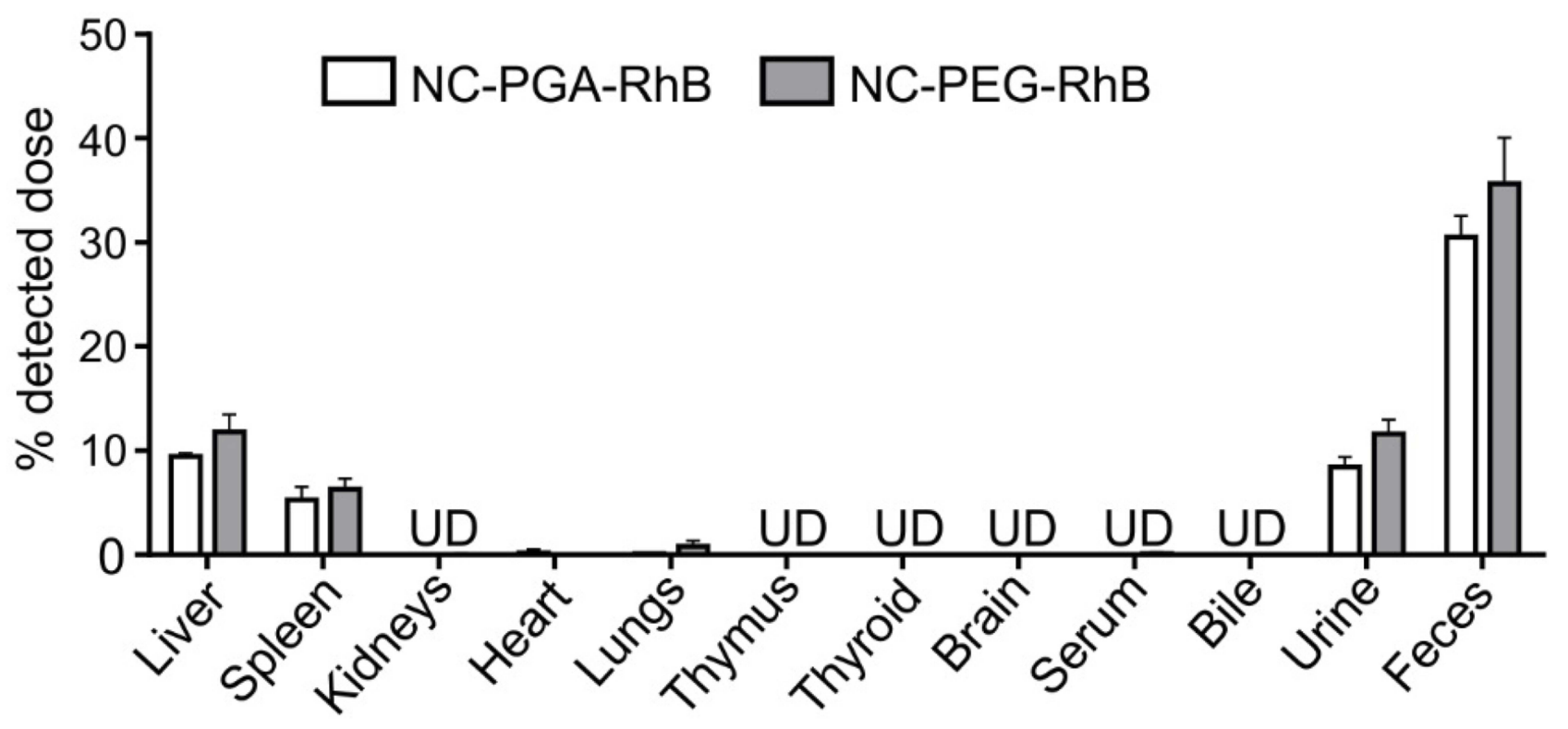

Figure 3 Biodistribution of fluorescently labeled polyelectrolyte nanocapsules after $24 \mathrm{hrs}$ exposure.

Notes: NC-PGA-RhB and NC-PEG-RhB or $15 \mathrm{mM} \mathrm{NaCl}$ were injected intravenously. Animals were placed in metabolic cages in purpose of collecting urine and feces. After $24 \mathrm{hrs}$ mice were sacrificed, and fluorescence was measured in serum, homogenates of major organs, and bile. Results are presented as the percent of the detected dose (see Methods). Fluorescence of 24-hrs total urine and feces is presented. UD, under detection limit. Bars represent mean \pm SD ( $=5$ ).

were measured in the liver $(9.4 \%$ and $11.8 \%$ of DD for $\mathrm{NC}$ PGA-RhB and NC-PEG-RhB, respectively) and in the spleen $(5.2 \%$ and $6.3 \%$ of DD for NC-PGA-RhB and NCPEG-RhB, respectively). Very weak fluorescence (less than $1 \%$ of DD) was measured also for the lungs and heart. After $24 \mathrm{hrs}$, fluorescence was not detectable in other analyzed organs, serum, or bile. Although fluorescence was not detectable in samples of urine, feces and bile gathered around the time of euthanasia, the measurements of fluorescence in the samples collected at different time points after nanomaterial injection enabled to identify the routes of removal of nanocapsules or products of their degradation (Figure 3, Figure S2 in Supplementary materials). The fluorescence of the whole volume of 24-hrs urine was $18.4 \%$ of DD for NC-PGA-RhB and $11.6 \%$ of DD for NC-PEG-RhB, which indicated that the nanocapsules or products of their degradation underwent renal clearance and were eliminated through urinary excretion. It is worth emphasizing that the renal clearance was a fast process; the highest fluorescence signals were measured for urine collected during the first 30 mins after nanocapsule administration (Figure $\mathrm{S} 2$ in Supplementary material). The fluorescence intensity of feces collected within $24 \mathrm{hrs}$ represented $30-35 \%$ of DD suggesting that the nanomaterial elimination occurred predominantly via the gastrointestinal tract (Figure 3). This notion was supported by the kinetics of fluorescence changes in the bile samples. The fluorescence signals reached maximum in bile 15 mins after nanocapsule injection and preceded those measured for feces, which peaked at the 4 hrs time point (Figure S2 in Supplementary material).

\section{Analyses of in vivo Toxicity of Polyelectrolyte Nanocapsules}

The potential acute and chronic toxicities of intravenously administered nanomaterials was analyzed via two experimental approaches, in which mice were injected with a single versus multiple doses of nanocapsules. In the first experimental setup, animals were sacrificed on the 1st, 7th, 30th and 60th days following the single NCPEG administration. The mice in the second experiment were injected with NC-PGA or NC-PEG every fourth day for 30 days and euthanized on the 30th or 60th day of the experiment. This experimental scheme allows to assess the short- and long-term toxicities of a single-dose of NC-PEG and the long-term toxicity of repeated applications of NCPGA or NC-PEG (Figure S1B in Supplementary material).

\section{Polyelectrolyte Nanocapsules are Not Hemotoxic}

We did not observe any alteration in animal behavior after injections or drop in a body weight (data not shown) or changes in sizes of main organs in mice injected with a single- or multiple doses of nanocapsules, which indicated that the nanomaterials did not have strong, systemic, toxic effects (Figure S3 in Supplementary material). They had 
also no effect on main hematological parameters evaluated for single dose (data not shown) as well as for multiple doses (Figure 4). Also, we did not observe the DNA damage analyzed for peritoneal macrophages and bone marrow (Figures 5 and $\underline{\mathrm{S} 4}$ in Supplementary material).

\section{Polyelectrolyte Nanocapsules Do Not Induce Liver-, Kidney-, or Spleen Failure}

Because the liver and kidneys were the main organs of NC-PGA and NC-PEG uptake and elimination, we analyzed potential hepato- and nephrotoxicity of the nanomaterials by the detailed biochemical analysis of sera collected just after euthanasia (on 1st, 7th, 30th and 60th days of experiment for single injection of NC-PEG, or on the 30th or 60th day of experiment for repeated injection of NC-PGA or NC-PEG). We measured total plasma protein and the activities of enzymatic markers of hepatotoxicity (alkaline phosphatase, alanine transaminase) as well as the levels of creatinine and blood urea nitrogen, which, when increased, indicate renal damage. The resulting values of all tested parameters were in the normal ranges and we did not observe any differences in any tested parameter between mice injected with nanomaterials vs control animals (Figures 6 and $\underline{\mathrm{S} 5}$ in Supplementary material). Additionally, we performed histological examination of the liver, kidney and spleen, which excluded significant architectural alterations and infiltration of tested tissues by immune cells (Figure 7).

\section{NC-PEG Stimulate Prolonged Upregulation of Different Cytokines}

The induction of cytokine synthesis in response to various nanomaterials is usually considered an undesirable effect that may lead to immunotoxicity manifesting, i.e. as severe autoimmunity. ${ }^{25}$ To evaluate the potential immune response to NC-PGA and NC-PEG, we examined the concentrations of selected cytokines in sera of mice injected with either nanomaterial and collected on the 1st, 7th, 30th and 60th days of experiment for single dose of NC-PEG and on the 30th or 60th day of experiment for NC-PGA and NCPEG in the multiple-dose scheme. The single dose of the nanocapsules had a weaker effect on the levels of the cytokines, and cytokine elevation was observed only after 30th and 60th day of experiment (Figure S6 in Supplementary material). In contrast, most tested cytokines were upregulated in animals injected repeatedly with NC-PEG, but not with NC-PGA. On the 30th day of experiment, we observed significantly raised levels of IL-23, IL- $1 \alpha$, IFN- $\gamma$, IL-12p70, IL-1 $\beta$, IL-10, IL-6, IL-17 $\alpha$ and GM-CSF. At that time, the concentration of TNF $\alpha$ was not elevated relative to the control, and the increases of MCP-1, IFN- $\beta$ and IL-27 levels did not reach statistical significance. Unexpectedly, the cytokine levels in sera of mice repeatedly injected with NC-PEG were even higher on 60th day of the experiment, clearly indicating that the PEGylated nanocapsules elicited a long-lasting immune response (Figure 8). NC-PGA injection did not result in elevated cytokine levels. Additionally, ELISA test performed on plates coated with PGA-g-PEG copolymer did not show the presence of anti-PEG $\mathrm{Ab}$ in sera from mice exposed to NC-PEG (Figure 9).

\section{Discussion}

The analysis of pharmacokinetic profiles and biodistribution is a crucial step in the development of nanocarriers proceeding evaluation of their biosafety and efficacy in drug delivery. ${ }^{26}$ To study pharmacokinetic profiles and biodistribution of iv-administered polyelectrolyte nanocapsules, we used rhodamine-labeled PGA-terminated nanocapsules (NC-PGA-RhB) and nanocapsules PEGylated with PLL-g-PEG (NC-PEG-RhB), obtained by the incorporation of rhodamine-labeled poly-L-lysine (PLL-RhB) into the polymeric shell. Because tested nanocapsules are biodegradable, measured fluorescence intensity may correspond to nanomaterial as well as to products of its degradation in vivo. Although previous tests performed in vitro confirmed high stability of the polyelectrolyte nanocapsules in serum, we cannot exclude that they had reduced stability in vivo due to hemodynamic forces and contacts with morphotic blood elements. Verification of this hypothesis requires further studies. ${ }^{24}$

In contrast to long-circulating lipid nanocapsules characterized by Hirsjärvi et al or liposomal nanoparticles containing polyelectrolyte layers built of poly-L-lysine and poly(ethylene glycol)-block-poly(L-aspartic acid) obtained by Ramasamy et al, both NC-PGA-RhB and NCPEG-RhB were quickly eliminated from the systemic circulation and from the body. ${ }^{27,28}$ Nanocapsule-derived fluorescence measured in serum in 240 mins (approximately $0.2 \%$ of DD) after nanomaterial administration was very low and was not detectable after the next 18 hrs. Our observations indicating fast nanocapsule clearance were similar to the results of Li et al, Saxena et al, and Garcia et al, which also concerned polymeric nanoparticles with rapid blood and organ clearance: PEGylated liposome-polycation-DNA nanoparticles, poly(D,L-lacticco-glycolic acid) and poly(D,L-lactic acid) nanocapsules. ${ }^{29-31}$ Interestingly, fluorescence intensity 


\section{$\triangle \mathrm{NaCl} \quad$ ONC-PGA $\square \mathrm{NC}-\mathrm{PEG}$}
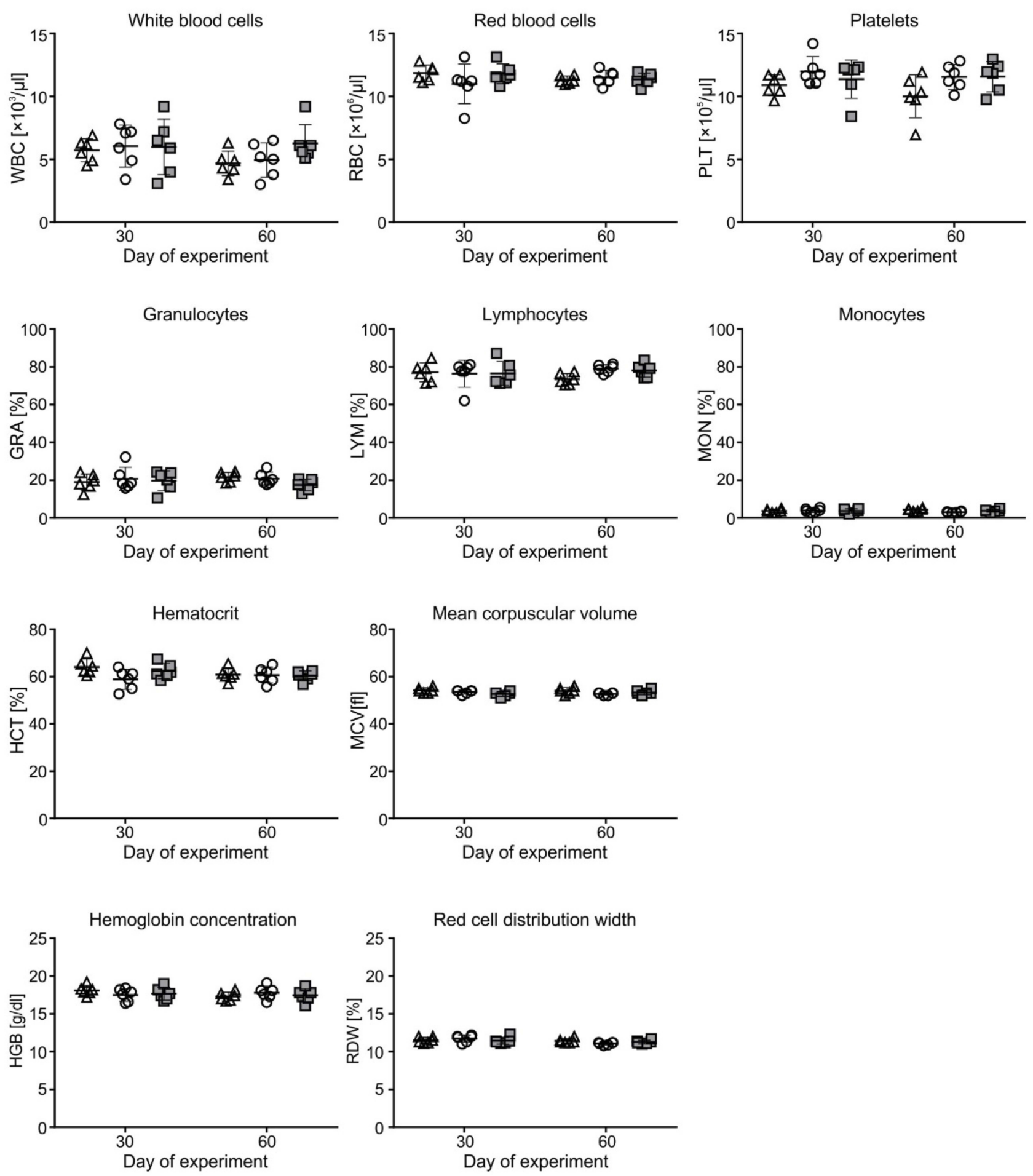

Figure 4 Analysis of hematotoxicity of polyelectrolyte nanocapsules after repeated intravenous administration.

Notes: Mice were injected intravenously with 8 doses of $15 \mathrm{mM} \mathrm{NaCl}$, NC-PGA or NC-PEG. Animals were euthanized on 30th or 60th day of the experiment, blood samples were collected from the facial vein and main hematological parameters were analyzed. Each point in graphs represents an individual mouse. The line for each group represents the mean $\pm S D(n=6)$. 
$\triangle \mathrm{NaCl} O \mathrm{NC}-\mathrm{PGA} \quad \square \mathrm{NC}-\mathrm{PEG}$
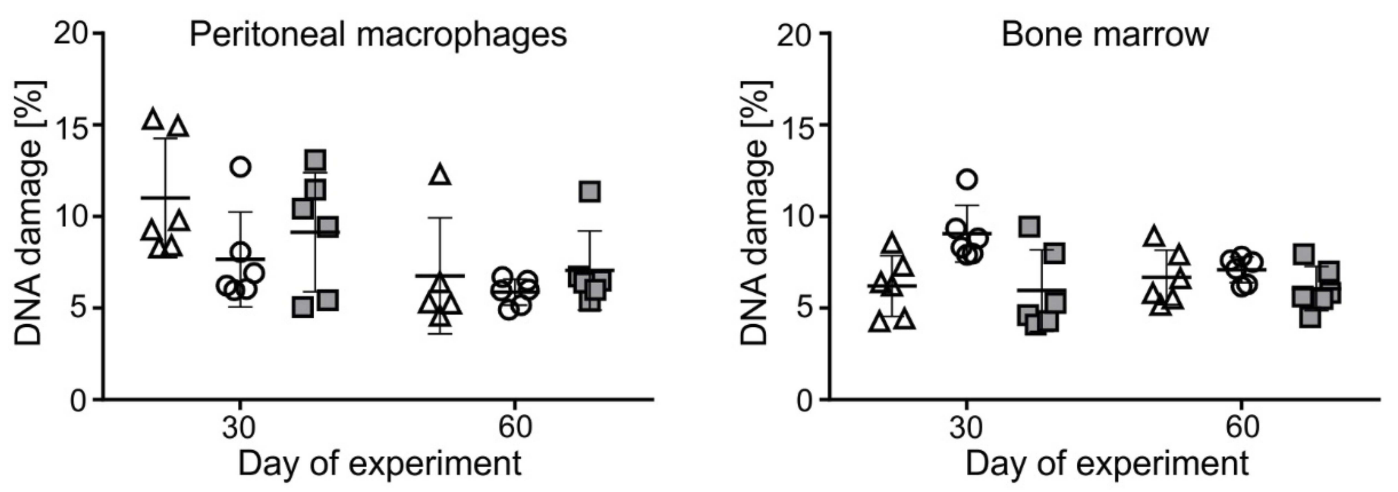

Figure 5 Comet assay of DNA damage after exposure of animals to 8 doses of polyelectrolyte nanocapsules.

Notes: Bone marrow and peritoneal cells were collected on 30th or 60th day of the experiment. Each point in graphs represents an individual mouse. The line for each group represents the mean $\pm S D(n=6)$. The percentage of DNA in the comet tail (\% DNA damage) was determined from two slides per sample with 50 randomly selected cells per slide.
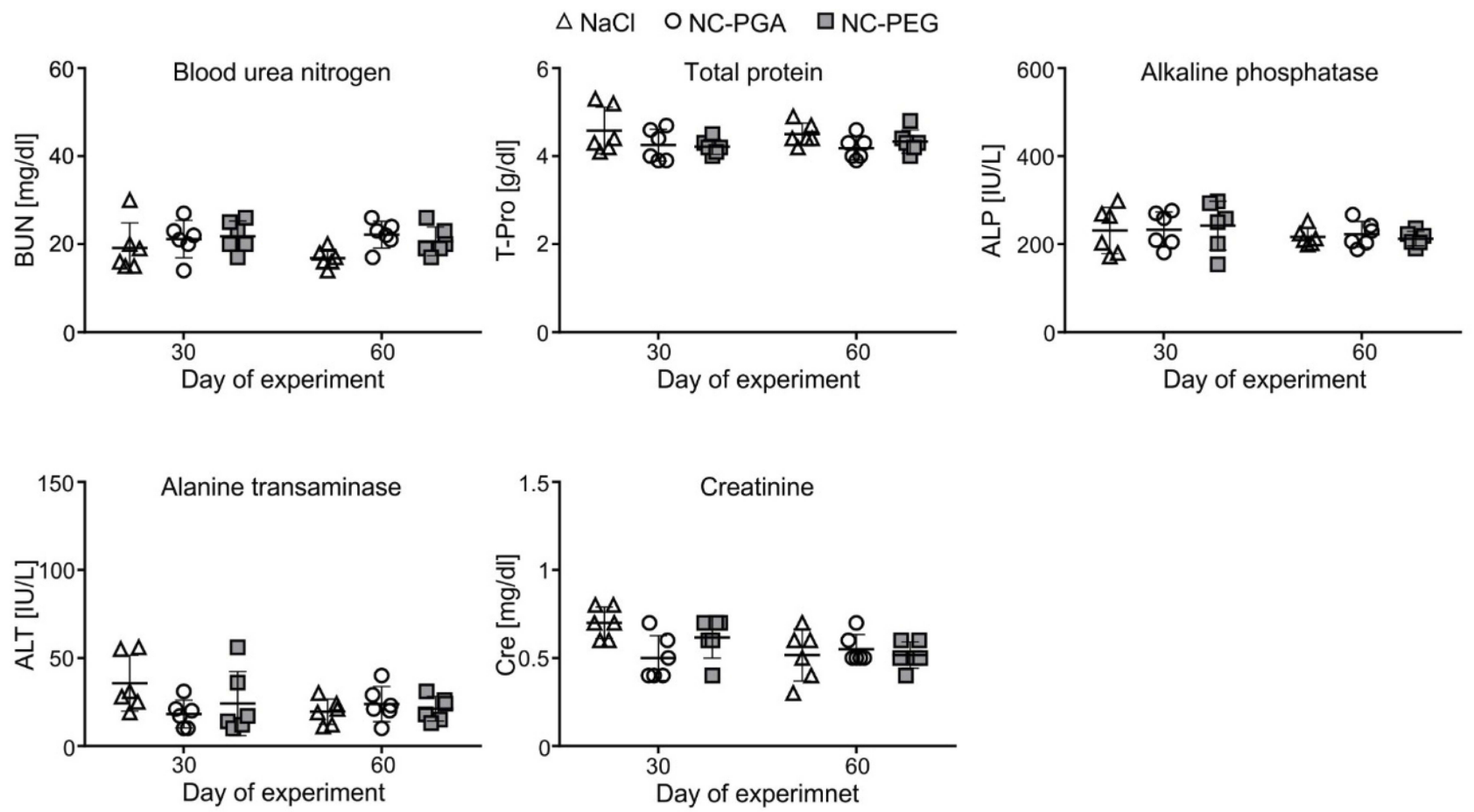

Figure 6 Biochemical analyses of sera isolated from animals after repeated administration of polyelectrolyte nanocapsules.

Notes: Animals were euthanized on the 30th or 60th day of the experiment, blood was isolated by cardiac puncture, and biochemical markers of hepatotoxicity and nephrotoxicity were analyzed in sera. Each point in graphs represents an individual mouse. The line for each group represents the mean \pm SD ( $=6$ ).

measured in the liver 3 mins after nanocapsule administration was similar to the one detected in serum. This high level of fluorescence in the liver resulted most probably from the rapid and intensive uptake of the nanocapsules by the liver cells and not from the strong blood supply to this organ. This hypothesis is supported by the results of Garcia et al, who compared the loading of nanomaterial in the non-perfused- and saline-perfused liver and did not observe significant differences in the label signals. ${ }^{31}$
Moreover, in contrast to serum, fluorescence of NC-PGA$\mathrm{RhB}$ and NC-PEG-RhB was still measurable in the liver and spleen $24 \mathrm{hrs}$ after nanocapsule administration, possibly due to accumulation of the nanomaterials in reticuloendothelial macrophages. ${ }^{32}$

Finally, we examined the pathways of excretion of the nanocapsules. Our results showed that nanocapsules or products of their degradation containing fluorescently labeled PLL are rapidly eliminated via hepatobiliary- and 
A
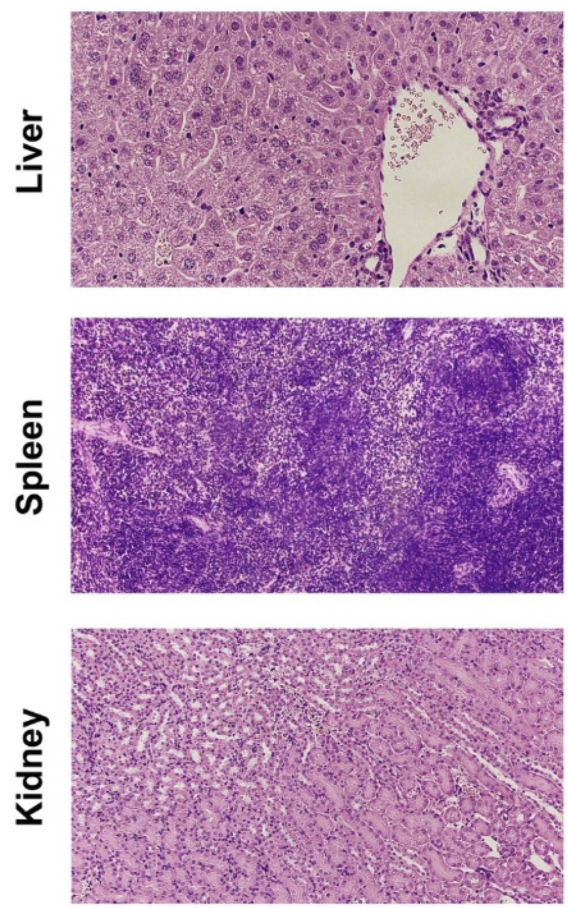

B
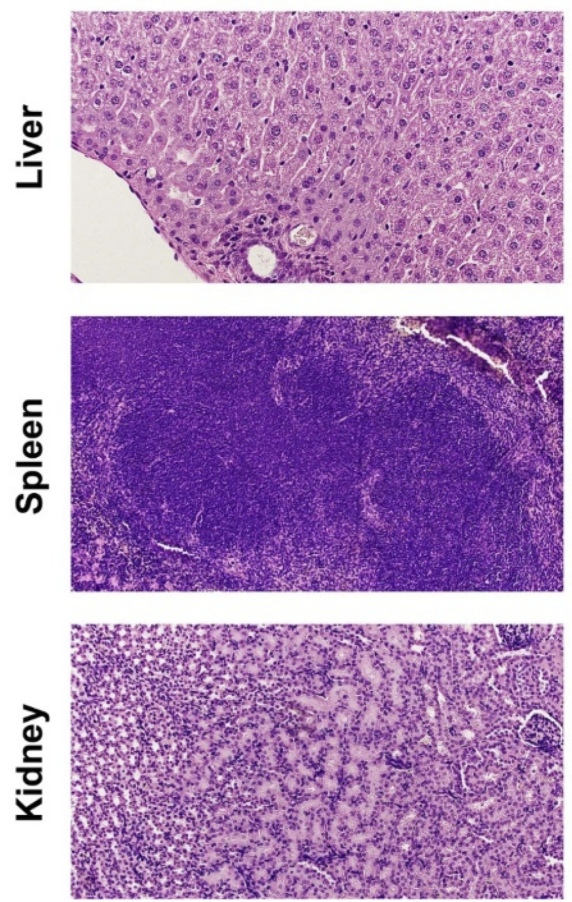

NC-PGA
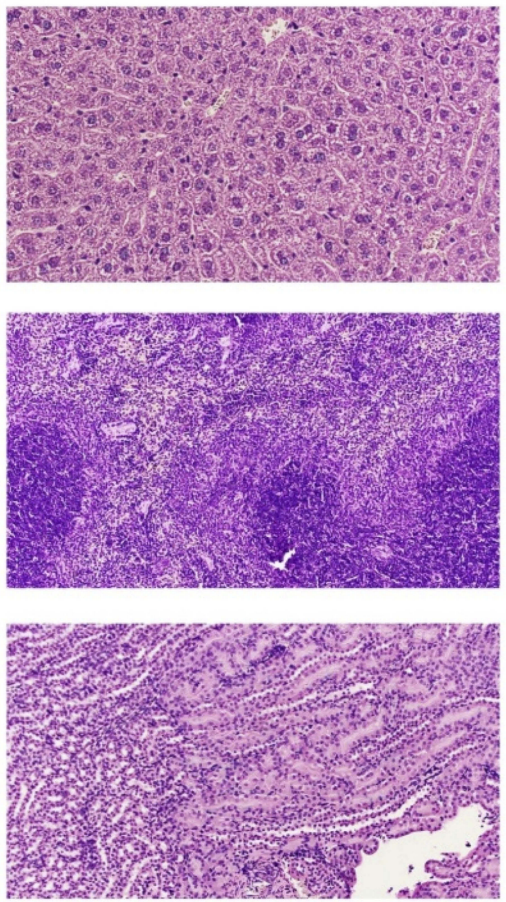

NC-PGA
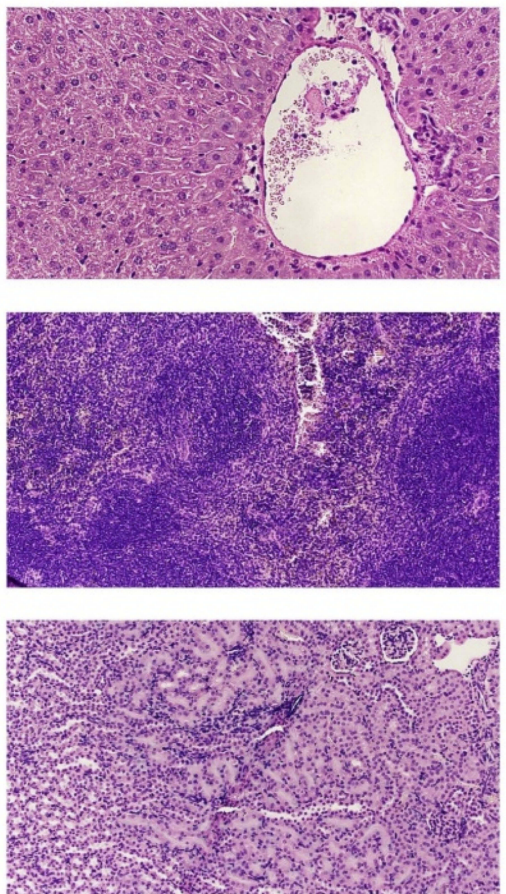

NC-PEG
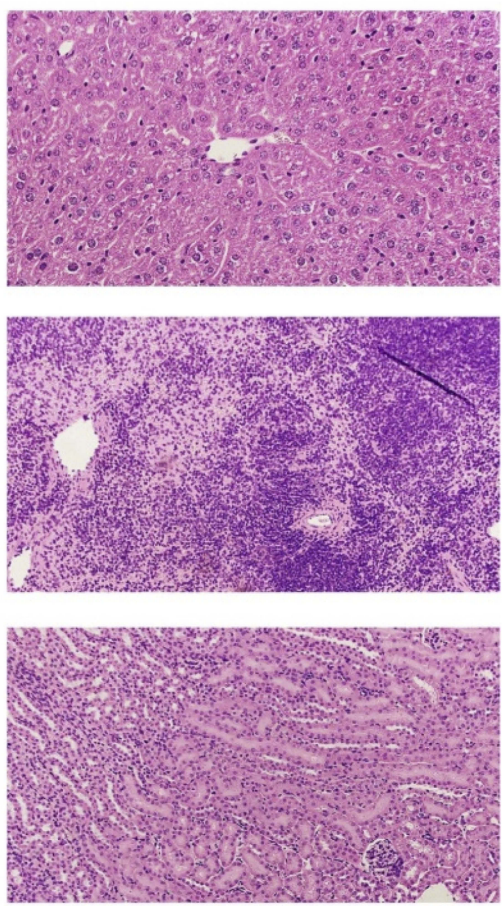

NC-PEG
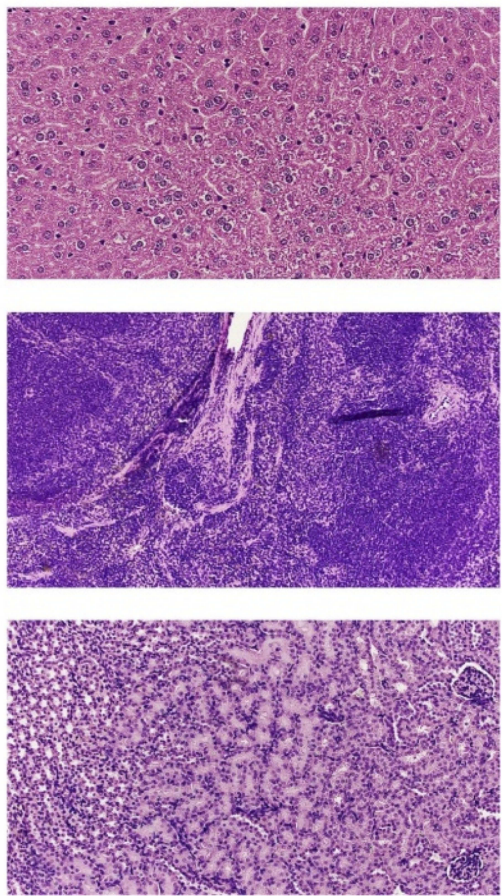

Figure 7 Histological examination of the liver, kidney and spleen isolated from animals after repeated administration of polyelectrolyte nanocapsules. Notes: Analysis was performed on (A) 30th or (B) 60th day of experiment.

to the lesser degree renal clearance. These observations may suggest that tested polyelectrolyte nanocapsules are taken primarily by hepatocytes, degraded and secreted into the bile. ${ }^{33}$
The nanocapsules differing in stealth polymers, PGA vs. PEG, showed identical pharmacokinetic, clearance, and biodistribution profiles. This is in accordance with recent findings that hydrophilic polymers other than PEG can be 
A
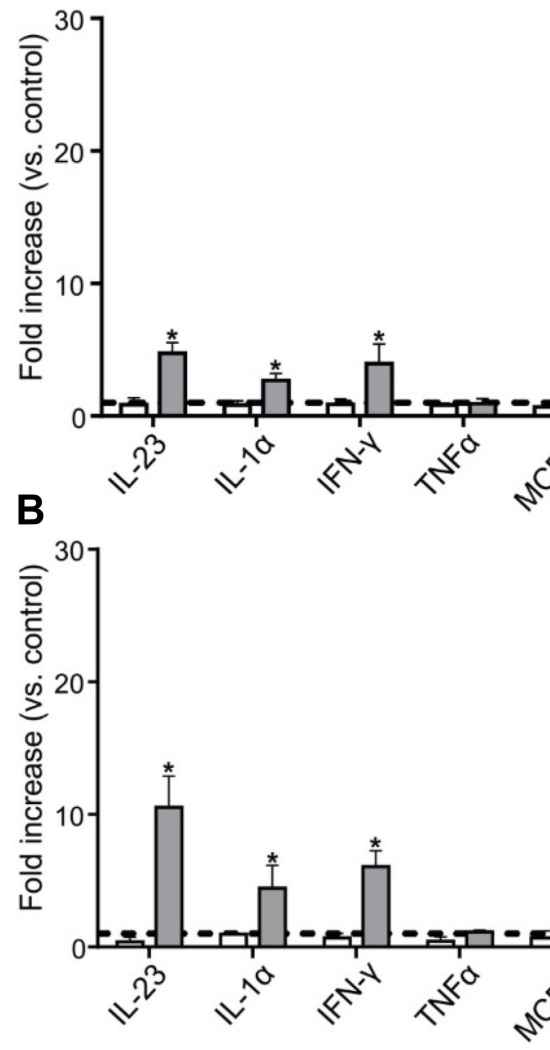

$\square$ NC-PGA $\square$ NC-PEG

$30^{\text {th }}$ day of experiment

Figure 8 Analysis of cytokine concentrations in mice sera after repeated administration of polyelectrolyte nanocapsules.

Notes: Cytokine concentrations in sera collected on (A) 30th or (B) 60th day of experiment were determined using LEGENDplex Mouse inflammation Panel kit and the $\mathrm{BD}$ LSRFortessa flow cytometer. Control level corresponds to cytokine concentrations in sera from mice injected with $15 \mathrm{mM} \mathrm{NaCl}$. Bars represent mean \pm SD ( $\mathrm{n}=5$ ). Statistical significance was analyzed by multiple-t-test.

\section{$\mathrm{NaCl} \square$ NC-PEG}

A

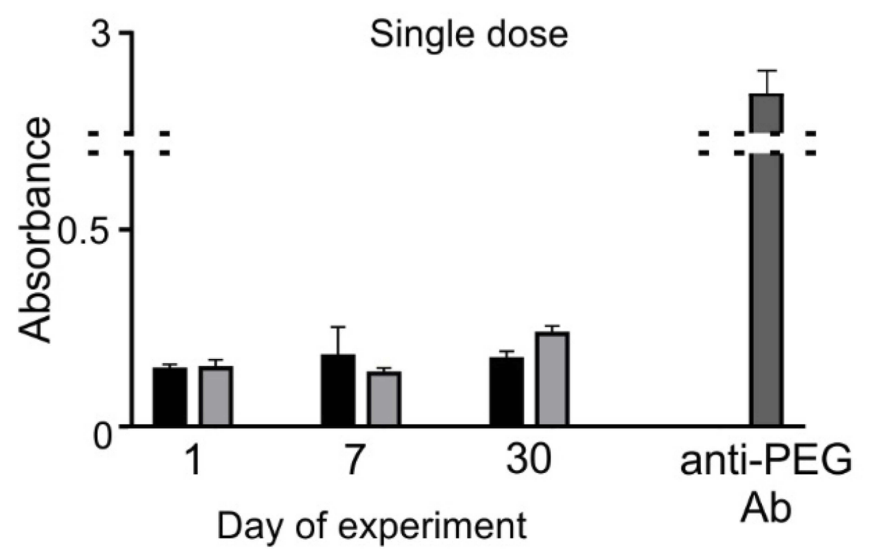

B

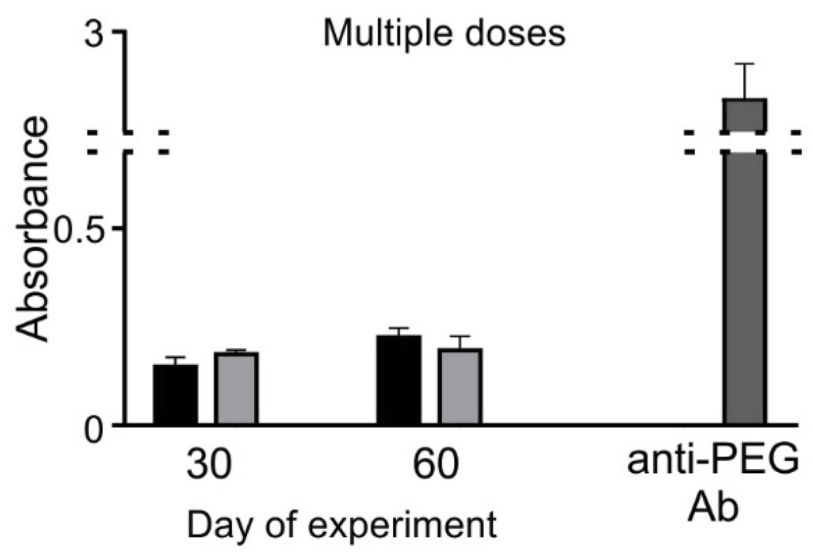

Figure 9 ELISA for analysis of humoral response to nanocapsules. ELISA plates were coated with PGA-g-PEG.

Notes: The presence of anti-PEG antibody in sera from mice injected with $15 \mathrm{mM} \mathrm{NaCl}$ or NC-PEG in: (A) the single dose- or (B) multiple doses scheme (see Methods) was probed with HRP-conjugated anti-mouse Ig. To prove proper coating of plates with the antigen, commercial anti-PEG Ab was used as a positive control. Bars represent mean $\pm S D(n=5)$. 
successfully used for the functionalization of nanomaterials. $^{34,35}$

We performed detailed studies on NC-PGA and NCPEG toxicity and because the nanomaterials are potential drug carriers, we examined the acute and chronic effects of a single and multiple doses of the nanocapsules. The lack of any signs of in vivo nanomaterial cytotoxicity towards blood cells and their bone marrow precursors is in line with the results of our previous in vitro studies, which demonstrated that NC-PGA and NC-PEG neither cause hemolysis of human erythrocytes, nor reduce the viability of human peripheral blood mononuclear cells (PBMCs), nor induce DNA damage in those cells after $48 \mathrm{hrs}$ exposure. Interestingly, NC-PGA, which was completely inert towards blood cells in vivo, showed in vitro a tendency to interact with human PBMCs and affect their morphology. ${ }^{21}$ This discrepancy can be explained by much longer exposure of blood cells to NC-PGA in vitro than in vivo. The fast plasma clearance of NC-PGA limits the interaction of blood cell with the nanomaterial reducing the risk of toxicity. We also analyzed hepato- and nephrotoxicity of NC-PGA and NC-PEG, because the liver and kidneys as the main routes of the nanocapsule clearance may be particularly vulnerable to nanomaterialmediated damage. We did not observe any changes in the morphology of the liver and kidneys. Also, the activities of the enzymes or concentrations of non-enzymatic markers of cholestatic injury (ALP) or hepatocellular injury (ALT, T-Pro) were normal. ${ }^{36}$ Similarly, the levels of serum Cre and BUN after NC-PGA or NC-PEG application allowed to exclude renal functional disturbance often observed in response to different nanomaterials. ${ }^{6,37}$ The lack of in vivo NC-PGA and NC-PEG hepatotoxicity is also in agreement with our in vitro studies, in which we demonstrated that the nanomaterials neither decreased viability, nor caused oxidative stress, nor DNA damage in the human cells of hepatic origin, HepG2 cell line. ${ }^{21}$

Our previous in vitro studies showed that the polyelectrolyte nanocapsules did not stimulate immune response. They did not activate mouse endothelial- as well as macrophage-like cells. ${ }^{21}$ In the present study, we did not detect any DNA damage in peritoneal macrophages isolated from mice treated with NC-PGA or NC-PEG. However, to further exclude in vivo immunotoxicity of the nanocapsules, we analyzed the serum levels of numerous cytokines, including proinflammatory ones. To our surprise, the analysis did not support our belief of absolute neutrality of nanocapsules towards the cells of the immune system. Although both single- and multiple doses of NCPGA did not result in increased plasma cytokine levels, single and particularly prolonged, multiple administrations of NC-PEG led to enhanced plasma levels of numerous cytokines including: IL-23, IL-1 $\alpha$, IFN- $\gamma$, IL-12p70, IL-1 $\beta$, IL-10, IL-6, IL-27, IL-17 $\alpha$, IFN- $\beta$, GM-CSF on the 30 th day of the experiment. The cytokine concentrations were even higher on the 60th day of experiment (a month after the last nanocapsule administration) than directly after finishing the series of injections suggesting the chronic character of the changes. This effect should be attributed to PLL-g-PEG because it was observed only for NC-PEG, and not NC-PGA. Many observations indicate the toxicity of nanomaterials built of PLL due to their positive charge. ${ }^{38}$ However, in the case of NC-PEG, the positive charge resulting from the presence of PLL is compensated by the PEG present on the surface of the nanocapsules. Therefore, we suggest that upregulated level of different cytokines results from intracellular accumulation of PEG in reticuloendothelial macrophages although, the fate of this polymer as well as possible side effects resulting from its accumulation in different cells or tissues is unknown. ${ }^{39}$ Although PEG has been considered nonbiodegradable, studies presented by Ulbricht et al indicated that PEG may undergo oxidative degradation. ${ }^{40}$ The question arises whether PEG itself or the products of its degradation may have pro-inflammatory properties and stimulate the production of cytokines by macrophages.

There are only a few works attempting to analyze the production of selected cytokines after administration of biodegradable nanomaterials and all are limited to shortterm (a few days) observations. For example, a single lung nebulization or intratracheal administration of different poly(D,L-lactide-co-glycolide) (PLGA) or nanoparticles composed only of PEG did not result in elevated cytokine levels in bronchoalveolar lavage 2 days later. ${ }^{41,42}$

There are many reports indicating that PEG attached to the nanocarrier surface or conjugated to therapeutic proteins carries the risk of immune response. ${ }^{43}$ In particular, several studies demonstrated the synthesis of antibodies of IgM class specific to PEG and suggested that these IgMs are responsible for the accelerated clearance of PEGylated nanomaterials, so-called accelerated blood clearance phenomenon $(\mathrm{ABC}){ }^{44}$ Ishida et al were able to detect antiPEG IgM antibody in mice and rats serum already after a single dose of intravenous administration of PEGylated liposomes. ${ }^{45}$ This phenomenon may lower therapeutic efficacy of PEGylated molecules and lead to serious side 
effects. Because of this, FDA has introduced guidelines to determine the level of anti-PEG antibodies in patients treated with such pharmaceuticals. Although in our studies NC-PEG was administered repeatedly to animals, we were not able to detect anti-PEG antibodies in mice serum. It is noteworthy that after single intravenous administration, the pharmacokinetics of NC-PGA and NC-PEG were identical. However, due to the fact that the mechanism of $\mathrm{ABC}$ phenomenon is not fully understood and we observed induction of immune response only to NC-PEG, different pharmacokinetics of NC-PEG and NC-PGA may be expected after repeated administration. Verification of this hypothesis requires further studies.

Our results show for the first time, that PEGylated, biocompatible, polyelectrolyte nanocapsules have immunostimulating properties manifesting in the upregulation of different cytokines including proinflammatory ones. Interestingly, in addition to increased cytokine levels, we did not observe any other side effects of NC-PEG. However, it should be emphasized that long-lasting elevated levels of cytokines can lead to inflammation-mediated toxicity. $^{46,47}$ For example, high levels of GM-CSF, IFN- $\gamma$, IL-23, IL-6, and IL-17 $\alpha$ were suggested to be involved in the development of organ-related autoimmune inflammatory diseases. $^{48}$

\section{Conclusion}

PEGylation of nanomaterials is still the most common method of their functionalization, despite the fact that PEG is not immunologically inert. Our results suggest that apart from canonical evaluation of anti-PEG antibody presence and complement activation, also the changes in cytokine levels observed long after administration of $\mathrm{NC}$ PEG could be indicative of PEG-mediated activation of the immune system. However, a precise explanation of this phenomenon requires further investigation involving other PEGylated nanomaterials and different PEGylation strategies. Based on cytokine analysis, we conclude that the tested polyelectrolyte nanocapsules coated with PGA may be safer than PEGylated ones, because, unlike the later, they do not stimulate an immune response. Moreover, our observations indicate the necessity of thorough analysis of a possible long-term immune response to all biodegradable nanomaterials.

\section{Acknowledgments}

The authors wish to thank Inga Drebot and Katarzyna Guła for their technical assistance with the animal experiments and prof. Piotr Warszyński for his helpful suggestions and discussion. This work was supported by the Diamond Grant number 0014/DIA/2014/43 to AK, funded by the Polish Ministry of Science and Higher Education. The Faculty of Biochemistry, Biophysics and Biotechnology of the Jagiellonian University in Kraków and the Jerzy Haber Institute of Catalysis and Surface Chemistry Polish Academy of Sciences were partners of the Leading National Research Center (KNOW) supported by the Polish Ministry of Science and Higher Education.

\section{Disclosure}

The authors report no conflicts of interest in this work.

\section{References}

1. Bobo D, Robinson KJ, Islam J, Thurecht KJ, Corrie SR. Nanoparticlebased medicines: a review of FDA-approved materials and clinical trials to date. Pharm Res. 2016;33(10):2373-2387. doi:10.1007/s11095-0161958-5

2. Blanco E, Shen H, Ferrari M. Principles of nanoparticle design for overcoming biological barriers to drug delivery. Nat Biotechnol. 2015;33(9):941-951. doi:10.1038/nbt.3330

3. Aleksiichuk V, Omelchuk S, Sokurenko L, Kaminsky R, Kovalchuk O, Chaikovsky Y. The influence of lead nanoparticles on the morpho-functional changes of rat liver during the postexposure period. Diaspro A, ed. Microsc Res Tech. 2018;81(7):781-788. doi:10.1002/jemt.23036

4. Stueckle TA, Davidson DC, Derk R, et al. Short-term pulmonary toxicity assessment of pre- and post-incinerated organomodified nanoclay in mice. ACS Nano. 2018;12(3):2292-2310. doi:10.1021/acsnano.7b07281

5. Shin JH, Jeon K, Kim JK, et al. Subacute inhalation toxicity study of synthetic amorphous silica nanoparticles in Sprague-Dawley rats. Inhal Toxicol. 2017;29(12-14):567-576. doi:10.1080/08958378.2018.1426661

6. Tiwari R, Singh RD, Khan H, et al. Oral subchronic exposure to silver nanoparticles causes renal damage through apoptotic impairment and necrotic cell death. Nanotoxicology. 2017;11(5):671-686. doi:10.1080/17435390.2017.1343874

7. Bahadar H, Maqbool F, Niaz K, Abdollahi M. Toxicity of Nanoparticles and an overview of current experimental models. Iran Biomed J. 2016;20(1):1-11. doi:10.7508/ibj.2016.01.001

8. Perret $\mathrm{P}$, Bacot S, Gèze A, et al. Biodistribution and preliminary toxicity studies of nanoparticles made of biotransesterified $\beta$-cyclodextrins and PEGylated phospholipids. Mater Sci Eng C. 2018;85:7-17. doi:10.1016/J.MSEC.2017.12.017

9. Bulcão RP, de Freitas FA, Dallegrave E, et al. In vivo toxicological evaluation of polymeric nanocapsules after intradermal administration. Eur J Pharm Biopharm. 2014;86(2):167-177. doi:10.1016/J.EJPB. 2013.04.001

10. Bojarová P, Tavares MR, Laaf D, et al. Biocompatible glyconanomaterials based on HPMA-copolymer for specific targeting of galectin-3. J Nanobiotechnol. 2018;16(1):73. doi:10.1186/s12951018-0399-1

11. Croissant JG, Brinker CJ. Biodegradable silica-based nanoparticles: dissolution kinetics and selective bond cleavage. Enzymes. 2018;43:181-214. doi:10.1016/BS.ENZ.2018.07.008

12. Shen Y-Q, Zhu Y-J, Yu H-P, Lu B-Q. Biodegradable nanocomposite of glycerol citrate polyester and ultralong hydroxyapatite nanowires with improved mechanical properties and low acidity. $J$ Colloid Interface Sci. 2018;530:9-15. doi:10.1016/j.jcis.2018.06.059 
13. Abd Ellah NH, Abouelmagd SA. Surface functionalization of polymeric nanoparticles for tumor drug delivery: approaches and challenges. Expert Opin Drug Deliv. 2017;14(2):201-214. doi:10.10 80/17425247.2016.1213238

14. Sathyamoorthy N, Dhanaraju MD. Shielding therapeutic drug carriers from the mononuclear phagocyte system: a review. Crit Rev Ther Drug Carrier Syst. 2016;33(6):489-567. doi:10.1615/CritRevTherDrugCarrier Syst.2016012303

15. Hu C-MJ, Fang RH, Luk BT, Zhang L. Polymeric nanotherapeutics: clinical development and advances in stealth functionalization strategies. Nanoscale. 2014;6(1):65-75. doi:10.1039/C3NR05444F

16. Bzowska M, Karabasz A, Szczepanowicz K. Encapsulation of camptothecin into pegylated polyelectrolyte nanocarriers. Colloids Surf A. 2018;557:36-42. doi:10.1016/J.COLSURFA.2018.05.070

17. Karabasz A, Bzowska M, Łukasiewicz S, Bereta J, Szczepanowicz K. Cytotoxic activity of paclitaxel incorporated into polyelectrolyte nanocapsules. J Nanop Res. 2014;16(4):2340. doi:10.1007/s11051014-2340-3

18. Szczepanowicz K, Bzowska M, Kruk T, Karabasz A, Bereta J, Warszynski P. Pegylated polyelectrolyte nanoparticles containing paclitaxel as a promising candidate for drug carriers for passive targeting. Colloids Surf B Biointerfaces. 2016;143:463-471. doi:10.1016/j.colsurfb.2016.03.064

19. Łukasiewicz S, Szczepanowicz K, Podgórna K, et al. Encapsulation of clozapine in polymeric nanocapsules and its biological effects. Colloids Surf B Biointerfaces. 2016;140:342-352. doi:10.1016/J. COLSURFB.2015.12.044

20. Piotrowski M, Jantas D, Szczepanowicz K, Łukasiewicz S, Lasoń W, Warszyński P. Polyelectrolyte-coated nanocapsules containing undecylenic acid: synthesis, biocompatibility and neuroprotective properties. Colloids Surf B Biointerfaces. 2015;135:8-17. doi:10.1016/j.colsurfb.2015.07.029

21. Karabasz A, Szczepanowicz K, Cierniak A, Bereta J, Bzowska M. In vitro toxicity studies of biodegradable, polyelectrolyte nanocapsules. Int J Nanomedicine. 2018;13:5159-5172. doi:10.2147/IJN.S169120

22. Hermanson GT. Bioconjugate Techniques. Elsevier Academic Press; 2008

23. Szczepanowicz K, Hoel HJ, Szyk-Warszynska L, et al. Formation of biocompatible nanocapsules with emulsion core and pegylated shell by polyelectrolyte multilayer adsorption. Langmuir. 2010;26 (15):12592-12597. doi:10.1021/la102061s

24. Lukasiewicz S, Szczepanowicz KP, Blasiak E, DziedzickaWasylewska M. biocompatible polymeric nanoparticles as promising candidates for drug delivery. Langmuir. 2015;31(23):64156425. doi:10.1021/acs.langmuir.5b01226

25. Elsabahy M, Wooley KL. Cytokines as biomarkers of nanoparticle immunotoxicity. Chem Soc Rev. 2013;42(12):5552. doi:10.1039/ c3 3 s $60064 \mathrm{e}$

26. Almeida JPM, Chen AL, Foster A, Drezek R. In vivo biodistribution of nanoparticles. Nanomedicine. 2011;6(5):815-835. doi:10.2217/nnm. 11.79

27. Hirsjärvi S, Sancey L, Dufort S, et al. Effect of particle size on the biodistribution of lipid nanocapsules: comparison between nuclear and fluorescence imaging and counting. Int $J$ Pharm. 2013;453:594-600. doi:10.1016/j.ijpharm.2013.05.057

28. Ramasamy T, Haidar ZS, Tran TH, et al. Layer-by-layer assembly of liposomal nanoparticles with PEGylated polyelectrolytes enhances systemic delivery of multiple anticancer drugs. Acta Biomater. 2014;10(12):5116-5127. doi:10.1016/J.ACTBIO.2014.08.021

29. Li S-D HL. Stealth nanoparticles: high density but sheddable PEG is a key for tumor targeting. J Control Release. 2010;145(3):178-181. doi:10.1016/j.jconrel.2010.03.016

30. Saxena V, Sadoqi M, Shao J. Polymeric nanoparticulate delivery system for indocyanine green: biodistribution in healthy mice. Int J Pharm. 2006;308(1-2):200-204. doi:10.1016/j.ijpharm.2005.11.003
31. Garcia GM, Oliveira LT, Pitta I da R, et al. Improved nonclinical pharmacokinetics and biodistribution of a new PPAR pan-agonist and COX inhibitor in nanocapsule formulation. $J$ Control Release. 2015;209:207-218. doi:10.1016/j.jconrel.2015.04.033

32. Zhang Y-N, Poon W, Tavares AJ, McGilvray ID, Chan WCW. Nanoparticle-liver interactions: cellular uptake and hepatobiliary elimination. J Control Release. 2016;240:332-348. doi:10.1016/J. JCONREL.2016.01.020

33. Longmire M, Choyke PL, Kobayashi H. Clearance properties of nano-sized particles and molecules as imaging agents: considerations and caveats. Nanomedicine. 2008;3(5):703-717. doi:10.2217/ 17435889.3.5.703

34. Abellan-Pose R, Rodríguez-Évora M, Vicente S, et al. Biodistribution of radiolabeled polyglutamic acid and PEG-polyglutamic acid nanocapsules. Eur J Pharm Biopharm. 2017;112:155-163. doi:10.1016/J.EJPB.2016.11.015

35. Gonzalo T, Lollo G, Garcia-Fuentes $M$, et al. A new potential nano-oncological therapy based on polyamino acid nanocapsules. $J$ Control Release. 2013;169(1-2):10-16. doi:10.1016/J.JCONREL. 2013.03.037

36. Wm A, Dw N, Ko O, Ngugi M, Enm N. Biochemical markers of in vivo hepatotoxicity. $J$ Clin Toxicol. 2016;6(2):297-305. doi:10.4172/2161-0495.1000297

37. Fuchs TC, Hewitt P. Biomarkers for drug-induced renal damage and nephrotoxicity - an overview for applied toxicology. AAPS J. 2011;13(4):615-631. doi:10.1208/s12248-011-9301-x

38. Hong S, Leroueil PR, Janus EK, et al. Interaction of polycationic polymers with supported lipid bilayers and cells: nanoscale hole formation and enhanced membrane permeability. Bioconjug Chem. 2006;17(3):728-734. doi:10.1021/bc060077y

39. Moghimi SM, Szebeni J, Stealth liposomes and long circulating nanoparticles: critical issues in pharmacokinetics, opsonization and protein-binding properties. Prog Lipid Res. 2003;42(6):463-478.

40. Ulbricht J, Jordan R, Luxenhofer R. On the biodegradability of polyethylene glycol, polypeptoids and poly(2-oxazoline)s. Biomaterials. 2014;35(17):4848-4861. doi:10.1016/J.BIOMATERIALS.2014.02.029

41. Aragao-Santiago L, Hillaireau H, Grabowski N, et al. Compared in vivo toxicity in mice of lung delivered biodegradable and non-biodegradable nanoparticles. Nanotoxicology. 2016;10 (3):292-302. doi:10.3109/17435390.2015.1054908

42. Roberts RA, Shen T, Allen IC, Hasan W, DeSimone JM, Ting JPY. Analysis of the murine immune response to pulmonary delivery of precisely fabricated nano- and microscale particles. Hussain S, ed. PLoS One. 2013;8(4):e62115. doi:10.1371/journal.pone.0062115

43. Neun B, Barenholz Y, Szebeni J, Dobrovolskaia M. Understanding the role of anti-PEG antibodies in the complement activation by doxil in vitro. Molecules. 2018;23(7):1700. doi:10.3390/molecules23071700

44. Cheng T-L, Wu P-Y, Wu M-F, Chern J-W, Roffler SR. Accelerated clearance of polyethylene glycol-modified proteins by anti-polyethylene glycol IgM. Bioconjug Chem. 1999;10(3):520-528. doi:10.1021/ BC980143Z

45. Ichihara M, Shimizu T, Imoto A, et al. Anti-PEG IgM response against PEGylated Liposomes in mice and rats. Pharmaceutics. 2010;3(1):1-11. doi:10.3390/pharmaceutics3010001

46. Kokkonen H, Söderström I, Rocklöv J, Hallmans G, Lejon K, Dahlqvist SR. Up-regulation of cytokines and chemokines predates the onset of rheumatoid arthritis. Arthritis Rheumatism. 2010;62 (2):383-391. doi:10.1002/art.27186

47. Gui S, Zhang Z, Zheng L, et al. Molecular mechanism of kidney injury of mice caused by exposure to titanium dioxide nanoparticles. J Hazard Mater. 2011;195:365-370. doi:10.1016/j.jhazmat.2011.08.055

48. Sonderegger I, Iezzi G, Maier R, Schmitz N, Kurrer M, Kopf M. GM-CSF mediates autoimmunity by enhancing IL-6-dependent Th17 cell development and survival. J Exp Med. 2008;205(10):2281-2294. doi:10.1084/jem.20071119 


\section{Publish your work in this journal}

The International Journal of Nanomedicine is an international, peerreviewed journal focusing on the application of nanotechnology in diagnostics, therapeutics, and drug delivery systems throughout the biomedical field. This journal is indexed on PubMed Central, MedLine, CAS, SciSearch ${ }^{\mathbb{B}}$, Current Contents ${ }^{\mathbb{B}} /$ Clinical Medicine,
Journal Citation Reports/Science Edition, EMBase, Scopus and the Elsevier Bibliographic databases. The manuscript management system is completely online and includes a very quick and fair peer-review system, which is all easy to use. Visit http://www.dovepress.com testimonials.php to read real quotes from published authors. 